\title{
Clinical research by GPs in their own practices
}

Having shown compelling evidence that clinical research by GPs in their own practices is now virtually extinct, Professor John Campbell Murdoch attributes this to journal policy, and asks for a new category, midway between "what is now regarded as a rigorous research paper and the pseudointellectual chatterings that occupy the "Back Pages"'.'

This imminent extinction is real, and deserves more thought than Murdoch seems to have given it. I have no doubt that if good clinical research by GPs in their own practices were submitted, the Editor would be delighted to publish it, but where is Murdoch's evidence that such research is being done? Production, not publication, is the problem, and reducing standards of rigour won't solve it.

He overlooks two huge obstacles to research of this kind, both of which could and should be eliminated. To do this will be demanding, but so is good research.

First, research by primary care and within primary care has no systematic funding. It's still regarded as a sort of personal hobby for unusual people which, like stamp collecting, should normally be unpaid. Modern GPs rightly work in groups, but with our present structure of business partnerships, these can only include real research (not pseudoresearch promoted by pharmaceutical companies) at their own shared expense. Partners who want to devote substantial professional time to research, and probably to work more obsessively and self-critically than their colleagues, have therefore to earn less for their partners as well as for themselves. Murdoch cites William Pickles of Aysgarth. What did his partner, Dean Dunbar, think of Pickles' devotion to research? By all local contemporary accounts, he cursed it. This does not necessarily reflect badly on Dunbar, there was a lot of work to do, more immediately urgent than adding to already incomprehensibly extensive knowledge. Then and now, when a partner pursues a single-minded interest not shared by colleagues in what is still an essentially commercial relationship, the others are likely at best to impede such work, at worst to ask the deviant to seek a more suitable academic post.

Could this be changed? Of course it could, if we had sufficient will and imagination. Partners no longer teach either their registrars or undergraduates without being paid for their teaching and preparation time, not too handsomely perhaps, but enough to satisfy all but the greediest partnerships. In 1966, the RCGP convinced the Department of Health that primary care was essential to a costeffective service, that its skills could and should be taught, and that continuing education should be funded by the NHS. Why can't the College do the same now for research? As Barbara Starfield and others have argued for many years, ${ }^{2}$ if we want results from routine care to approach those from experimental care in clinical trials, we must have research on generally older people with multiple pathologies, leading their ordinary lives. ${ }^{3}$ This is essential for a cost-effective service. Essentially, the same arguments apply as in 1966.

The numbers needed to produce valid results are far beyond even the largest group practice, so these would have to be multicentre trials, but we proved we could organise those long ago, in Clifford Kay's Oral Contraceptive study. ${ }^{4}$

Research of this sort needs high response rates - at least $85 \%$ - because the greatest difficulties in delivering care effectively are concentrated in people least likely to volunteer for clinical trials. High response rates were a feature of nearly all the most influential GP-initiated research studies published from 1960 to 1990 before the changes which Murdoch deplores. They were obtained because research-oriented GPs were enthusiasts who, having created trusting relationships by personal example, were able to transmit their enthusiasm to their patients. We were not afraid to mobilise local public opinion in support of participative scientific enquiry. We were proud to belong to a nation which made medical knowledge available free to every citizen. We could therefore reasonably expect all but a very few patients to assist in expanding that knowledge, as a shared good for everyone - and GPs who knew their patients were in an exceptionally good position to judge who these few were likely to be, and leave them alone.

Despite three decades of political and commercial brainwashing, that generous view is still shared by most people, who do not yet equate citizens with consumers. Unfortunately, it seems not to be shared by most ethical committees, which have generally accepted uncritically a division between providers and receivers of care similar to commercial transactions between salespersons and consumers. They therefore see themselves as guardians of the public interest, whose task is to protect patients from the Frankensteins they seem to imagine research-oriented GPs to be.

The practice manager of my former practice retired last year, after a lifetime of service with me and two of my successors. In our unit attached to the Medical Research Council, we had worked together on several studies published in major peer-reviewed journals, and she was a co-author of two of them. In her last few years she worked for a Master's degree requiring a research dissertation. After advice from several experienced and influential researchers, she chose to study the tendency of a substantial minority of patients to collect prescribed medications, but then to accumulate rather than swallow them, a process already researched in the classic study by Dunnell and Cartwright, whose work provided an excellent design frame. ${ }^{5}$ The Neath and Port Talbot ethical committee turned this proposal down flat, on the grounds that it would intrude on the personal rights of patients, that the committee believed she would share her data with her GP-employer and thus threaten patients' relationships with him (although she had assured the 
Committee that she would preserve confidentiality), and finally that no practitioner was ever justified in conducting research on their own practice population, because their truly voluntary participation could not in such circumstances be assured. Reluctantly, on my advice she appealed. Three months before the dissertation had to be completed, the committee decided she could go ahead, but only if she did her research in another practice, whose patients she did not know. I have discussed this case with several colleagues in different parts of the UK. They all had similar experiences. Ethical committees apparently exist to castrate research in primary care, before it has a chance to breach the independence of consumers.

Multicentre studies on and with participating patients, conducted peripherally by primary care staff with personal knowledge of and responsibility for those patients, and coordinated centrally by groups including both fully trained researchers and experienced primary care staff, provide the only possible sites for research on patients as they actually are, where they actually live, which we must have for guidelines to become optimally effective aids to clinical decisions. This could and should be a huge new growth area for research, but it won't happen unless either the College or some other agency, such as the MRC, make it happen, and get NHS funding on the large scale necessary to support it. The appointment of Sir Leszek Borysiewicz as a socially imaginative chief executive of the MRC was an important step in the right direction. Experience of the MRC General Practice Research Framework since the 1970s has already shown a little of what can be done, though its reluctance to tell the general or even professional public about it has been incomprehensible. I have no idea what the research committee of the College does nowadays, but in my time it seemed to function only as an occasional meeting between the three or four minor GP research empires scattered about the UK to divide whatever cake was available. The idea that the College could actually develop a research policy for primary care throughout the NHS never seemed to reach its agenda. As for cooperation with the MRC, that was apparently as unthinkable as peace in the Middle East - perhaps for similar reasons.

Murdoch's data should be at the top of the agenda of College Council, not to open the journal to more hunches, anecdotes, and handwringing about bad policies we do little to change, but to revive a tradition of intelligent questioning by giving it new, more collective and inclusive forms, properly funded by the NHS.

\section{Julian Tudor Hart}

\section{REFERENCES}

1. Murdoch JC. The end of practice-based research? $\mathrm{Br}$ J Gen Pract 2009; 59 (558): 52.

2. Starfield B. New paradigms for quality in primary care. Br J Gen Pract 2001; 51(465): 303-309.

3. Hart JT. Commentary: Can health outputs of routine practice approach those of clinical trials? Int $J$ Epidemiol 2001; 30: 1263-1267.

4. Kay CR (ed.). Oral contraceptives and health: interim report. London: Royal College of General Practitioners, 1974.

5. Dunnell K, Cartwright A. Medicine takers, prescribers, and hoarders. London: Routledge \& Kegan Paul, 1972.

DOI: 10.3399/bjgp09X420149

\section{Note to readers}

As a result of editorial incompetence, RCGP officers were not given an opportunity to respond alongside. We're happy to reassure readers that there will be a response in the April issue - Ed. 